\title{
Modern technologies of teaching economics in the context of the principles of sustainable development
}

\author{
Mariya Kivarina* \\ Yaroslav-the-Wise Novgorod State University, 173001 Veliky Novgorod, Russia
}

\begin{abstract}
Currently, a new concept of education is being actively formed as a factor in observing the principle of sustainable development. Sustainable development goals can be achieved by an active and dynamic society that cannot be formed in traditional educational systems. The article discusses the features of the imitation game as a strategy for teaching economic disciplines in higher education. The goals and functions of the imitation game are highlighted, its results and competencies are formulated. Role-playing and business games are considered as two main types of imitation games. Their comparative characteristics are carried out, the advantages, disadvantages and distinctive features of each type are highlighted. The phases (periods) of imitation games from preparation for the game to summing up its results have been investigated, the structure of the course of the game in the classroom in economics has been studied. It is proved that in the case of using an imitation game in the classroom on economics, the result of the educational process is the intertwining of theoretical and practical skills, which brings students closer to economic reality and develops the competence of optimal behaviour strategies in their professional activities.
\end{abstract}

\section{Introduction}

Currently, much attention is paid to new ways, methods, and techniques of teaching in higher educational institutions of various disciplines in order to familiarize students with the principles of sustainable development. Economics is one of these disciplines. It is impossible to reveal the features of teaching economics without researching the subjectdidactic elements of this process. The choice of a specific method of teaching students is based on the optimal combination of elements of general didactics, didactics of economics as a studied subject, and methods of teaching it. The effectiveness of the chosen teaching method is determined by the correctly selected ratio of the above components.

A feature of the methods described in the article is the active role of students involved in economic situations and problems through modeling the practical conditions of management. Thus, the learning process is transformed from static to dynamic, which

\footnotetext{
*Corresponding author: mariya.kivarina@novsu.ru
} 
contributes to the development of competence in students of optimal strategies of behavior in the future.

The purpose of the article is to study the features of the imitation game as a strategy for teaching economic disciplines in higher education, and to prove that if imitation games are used in economics classes, the result of the educational process will be an interweaving of theoretical and practical skills of students, which will allow them to make effective decisions in their professional activities.

\section{Materials and Methods}

The methodology of teaching economics is based on didactics, which can be defined as the theory of learning. If the methodology answers the question "how to teach?", Then didactics stops at the question "what to teach?" and this question is primary. Consequently, the author's approach to understanding the methodology is based on its integration into the general didactic concept of teaching economics in higher education.

Didactics can be viewed from three points of view. On the one hand, this is the theory of goals, which explains how to give a single general meaning to a multitude of dissimilar phenomena, processes, and objects. On the other hand, didactics is a theory of the process, since with its help the construction of the entire educational process is carried out based on an analysis of curricula. Finally, the third interpretation reduces didactics to the theory of action, since it contributes to the development of the teacher's ability to plan, conduct, and analyse the lessons conducted.

The author distinguishes between general didactics and didactics of a subject, implying a teacher-guided reflection of certain sections of a particular subject, for example, economics. Unlike general didactics, the didactics of a subject explores its scientific structures and independently develops in all three of the above aspects [1].

The separation of the didactics of the subject from the general didactics allows the author to talk about the independence of the methodology of teaching economics. There are various interpretations of the teaching method in the scientific literature. Some researchers emphasize the primacy of the goals of the teaching method. Other authors focus on the content of the learning process. The author's approach is based on a reasonable synthesis of the above approaches (Figure 1).

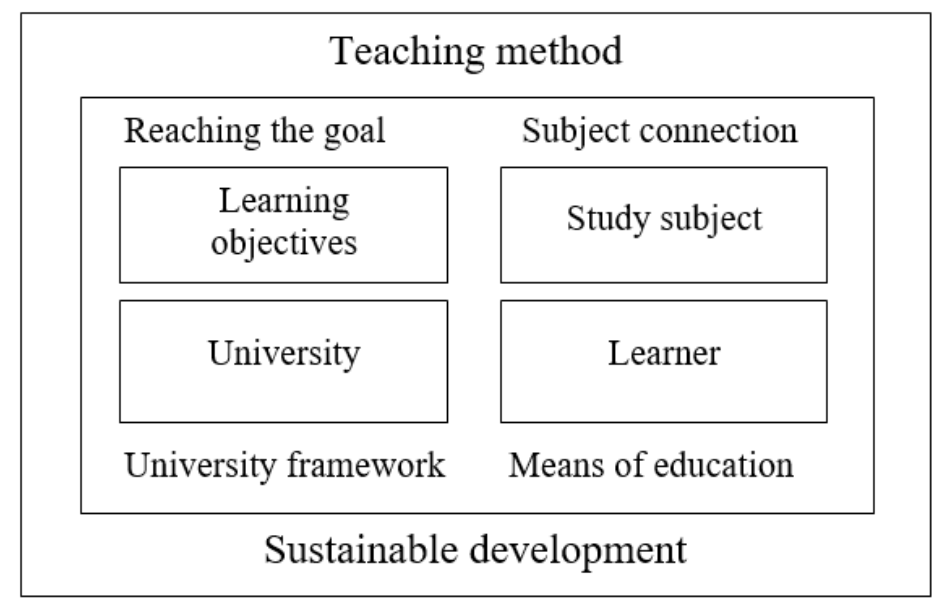

Fig. 1. Planes of definition of a training lesson. 
The plane "reaching the goal" indicates the use of the method as a means of achieving learning objectives. The plane "subject connection" allows you to emphasize the relationship between the teaching method and the content of the subject. The plane of "means of education" focuses on the formation of favourable conditions for learning. Finally, the plane of the "university framework" allows you to see the systematic nature of teaching, emphasizes the importance of the university as the main institution organizing the entire learning process.

\section{Results}

The imitation game as a teaching strategy in higher education allows you to transform the form of organization of the educational process from retransmission of theoretical knowledge from the teacher to the students to imitation of the studied contradictions and intractable situations from the life of society in the form of play activities [2]. Particular interest in the format of imitation games in higher education is due to the presence of an objective connection between game plots and life situations that arise in a real economic environment, which allows students to learn the patterns and cause-and-effect relationship of economic events. Thus, students have the opportunity in an artificially simulated environment to prepare for making optimal economic decisions in the future.

The term "imitation game" is based on a variety of learning strategies that combine such game elements as competition, cooperation, competition, specialization, synergistic effect, which directly or indirectly form the signs of imitation, reflecting the characteristic features of reality [3].

The goals of using the imitation game as an educational, methodological, and didactic technique in classroom lessons in higher education are to implement the following functions:

- Familiarization function - allows you to familiarize students with specific contradictions and conflict situations that arise in labour, economic, economic or professional activities;

- Developing function - allows students to develop specific strategies for behaviour in contradictory and conflict situations, develops the ability to overcome conflicts;

- Proactive function - develops the ability of students to respond appropriately to contradictions and conflicts in a real economic environment, to make effective decisions that minimize the negative consequences of conflict situations.

The result of using imitation games in the learning process is the formation and development of students of such unique abilities as:

- the ability to timely recognize conflict situations and overcome them in the best way;

- expanding the range of activities and developing additional skills and abilities that are in demand in today's dynamically developing economic environment;

- understanding, awareness and competent interpretation of the consequences of social activity;

- critical examination, control, and adjustment of one's own point of view about personal and other people's value systems.

Role-based activity in the sense of defining roles as an interactive action, in addition to knowing the requirements for a role, involves four key competencies:

- communicative competence: the ability to express one's intentions and needs in such a way that they are understood by the interacting party;

- competence of self-determination: each student positions himself and determines his attitude to the role performed. In the course of a business game, it is extremely important to learn to distance yourself from the role, to perform the function of an outside observer, questioning the actions and decisions of the character being played; 
- competence of empathy: the ability to empathy, sensitivity, responsiveness to the characters of the game, the ability to enter the position of the other side, to understand and feel his motives and expectations;

- tolerant competence: tolerance in relation to contradictory situations, the ability to accept the expectations of other players and ambiguous situations, as well as interact even in cases where one's own needs are not met in the best way.

A didactically prepared imitation game confronts students with a given economic contradiction or a conflict and problem situation, which must be resolved in a playful way.

The simplest form of imitation play is role-playing games, characterized by a relatively low level of formalism, as well as a narrow range of reactions, usually structured by players or a teacher. Role-playing games enable learners to experience social forms of behaviour in game situations close to reality, without fear of serious sanctions in case of finding the wrong model of behaviour [4].

The most important conditions for the successful use of role play in the educational process are transformation of simple actions of students into interactive ones, more complex in their essence and content; qualitative modelling of initial situations, implementation of the principle of scientific correctness; deep involvement of students and teachers in an active class format. Only in such conditions will role play be able to develop spontaneously, show various variations, and reveal the scientific interest and creative potential of students [5].

At the same time, learning is transformed from a classical controlled process into a controlled random one. And here it is important to find a compromise: although the roleplaying game, in order to obtain the best results, should mainly take place in a free, relaxed form, the teacher still cannot completely lose methodological control over the educational process. Therefore, in the course of using role-playing games in economics classes, the role of a teacher in higher education is transformed. He is required to possess new competencies such as intuition, flexibility, quick response, and tolerance. The teacher must clearly and impartially follow the course of the business game, be extremely careful in his statements and criticism regarding the process taking place in the classroom, direct the game, direct, but not interfere with the students. The function of the head of a business game allows the teacher to choose game situations, organize the process of assigning and changing roles, and managing discussion and reflection at the end of a training session.

Business games are an alternative form of imitation game [6]. As a prototype of business games, they call war games, which have been known to world history since antiquity. Any business game is based on the imitation process and two key elements: the model and the game itself.

The model is a kind of simplified reality, where there is an abstraction from factors that are irrelevant for the purposes of occupation. It sets the framework for the game and thus creates a base for it, while the game gives learners the opportunity to make specific decisions within the boundaries of a given model. V. Grimm defines a business game as a special way of teaching that enables students to learn how to make decisions within a specific model, as well as check their effectiveness based on the results achieved over a certain period.

In the process of a business game, trainers make various management, financial, economic decisions within the framework of a specific given model. The initially formed static model is transformed into a dynamic one and can change its original form, in the same way as the economic reality itself changes under the influence of certain actions of economic agents.

Consequently, a business game can be viewed as an imitation of the decision-making process at specific time intervals that are relevant to the given conditions of the model. Any decision made by the players to end the game or game episode must be discussed with the 
fixation of the results to which it led. This will allow the formation of cause-and-effect relationships and critical thinking in students. During such reflection, a variety of conclusions, ideas, solutions can arise that can be used in the next episode of the game or in future game models.

Any business game is based on a certain scenario, which can be divided into phases (periods) of the game. There are three key phases: preparation for the game, the game itself and the summing up of the game. The study of these periods allowed the author to determine the structure of business games. The main elements in the structure of a business game are:

- Acquaintance with the conditions of the game, with the initial economic situation, which allows students to comprehensively understand the key problem of the game, as well as the interests of each of the players.

- The distribution of roles among the participants, taking into account the identified interests of the players, familiarity with the strengths and weaknesses, capabilities and weaknesses of the characters.

- Acquaintance with the model and the mechanism of the game, clarification of the questions that have arisen on the scenario or conditions, determination of significant strategies of behavior for the players.

- The process of the game, as the implementation of the behavior strategies chosen by the students within the framework of the given conditions.

- Summing up (reflection), during which the course of the game, its possible alternatives, decisions made by the players and their consequences are discussed. Here, an analysis of the business game is carried out, where you can remove the limitations adopted in the model and compare the behavior of the model with reality. Reflection can result in a critical assessment of decisions made in the game or a modification of the original model.

Summarizing the above, the following key components of a business game can be distinguished [7]:

- rules of the game - restrictions that predetermine the framework of the model and the actions of the players;

- relevant period - a period of time during which the consequences of a given decision are worked out;

- active actions of students - fill the initially static model with dynamics;

- the active role of the teacher - the holder of the game, the arbiter, allowing you to see the results required by the educational process.

- reflection - a critical assessment of the results of the lesson.

Thus, in the case when the simulation game forms the basis of a dynamic educational process in economics classes, the theoretical knowledge and practical skills of students are intertwined, which brings them closer to economic reality and develops the competence of optimal behaviour strategies in the future.

\section{Discussion}

In modern conditions, higher education faces many challenges and contradictions. Changes are taking place in the state-political system of Russia, the socio-economic conditions of society are being transformed. Such objective processes of modernity as globalization, internationalization, integration, liberalization continue. There is a formation and development of a market economy with its advantages and disadvantages. And higher education one way or another is forced to react to all the above and other events $[8,9]$.

Teaching economics in higher education is turning from a passive to an active process. Non-imitative teaching methods, such as lectures, seminars, discussions, are transformed 
into a special group of active methods, which is based on the involvement of students in a simplified reality.

Play is one of the perfect types of human activity, embodying all the principles of educational and cognitive activity. This is a unique mechanism for the accumulation and transfer of social experience. The game allows students not only to learn how to acquire the necessary knowledge, but also to use it in specific practical conditions. That is why simulation and business games have become such a popular active learning method today [10].

Proponents of active teaching methods note that imitation educational games solve several strategic tasks: they speed up and facilitate the processes of memorizing information; form the skills of decision-making in difficult conditions, management of multicomponent systems; give a personal meaning to socially significant problems [11]. At the same time, students have the opportunity for self-knowledge, an increase in the degree of reflexivity, self-confidence, and self-esteem [12].

Opponents of the use of active methods of teaching economics note the lack of fundamental knowledge and systems thinking among students and talk about the difficulties of modeling educational situations that could fully present and reveal educational material [13]. To practice specific practical skills, the simulated situation should be taken from life or as close to it as possible. However, the economic reality is complex and multifaceted. Therefore, training models are often greatly simplified and far from reality [14].

Despite these difficulties, new methods of teaching economics in higher education are becoming more and more popular. Trying on any role, students enter a variety of interpersonal relationships, learn to interact in society, respond to difficulties and make decisions quickly [15]. The formation of the listed competencies is the key to successful professional activities of students in the future.

\section{Conclusions}

Thus, teaching economics in higher education is a complex process based on both classical and modern teaching methods. Among modern methods, simulation and business games play a special role.

In the process of passing a simulation or business game, all its participants are trained in a certain simulated space. The result of such activities is an increase in the level of student involvement in the educational process and an increase in student motivation.

The use of active teaching methods allows students to engage in cognitive and analytical processes using non-standard thinking, creative approaches that captivate students and develop their imagination. At the same time, one should not forget about the fundamental aspects of economics. It is important to focus students' attention on the basic principles of economics and to trace the relationship of the studied processes and phenomena with key theoretical provisions.

It is important not to forget about the need for the formation of systems thinking in future economists. In a rapidly changing reality, growing restrictions in the external and internal environment, systems thinking is the most important competence of modern graduates of economic fields. Only a comprehensive look at the economy, problems and prospects for its development will help graduates make adequate and competent decisions.

As a result, we can conclude that only the joint use of both classical and modern methods of teaching economics is able to find new ways to solve urgent practical problems. Economic practice is complex and varied. In the interests of sustainable development, it is educational technologies and processes that are priority and most significant. The use of active methods of studying economics should become one of the key elements of the concept of sustainable development. 


\section{References}

1. L.P. Sazhneva, I.A. Borisova, M.V. Kivarina, EpSBS. CIEDR 2018 - Future Academy, 8 (2019)

2. T. Kikuchi, Y. Tanaka, M. Kunigami, T. Yamada, H. Takahashi, T. Terano, Debriefing Framework for Business Games Using Simulation Analysis, 6936-08, (2019)

3. H. Ellington, E. Addinall, F.Percival, A handbook of game design (Kogan Page, Nichols Publishing Company, 1982)

4. A. Faria, Simulation and Gaming, 32, 97 (2001)

5. A. Hübl, G. Fischer, Proceedings of the 2017 Winter Simulation Conference (WSC), 8248129 (2017)

6. N. Baldissin, A. De Toni, F. Nonino, What is a Business Game? Historical background and evolution of business games in serious games context (ISBN: 97812913225522013, 2013)

7. J. Edman, I. Ståhl, SSE/EFI Working Paper Series in Business Administration, 8 (2002)

8. J. Wolfe, D. Crookall, Simulation and Gaming, 29, 7 (1998)

9. T. Crookall, W. Thorngate, Simulation \& Gaming, 40(1), 8 (2009)

10. A. Lacruz, RAM, 18, 49 (2017)

11. A.V. Zaykova, Psychological support of educational simulation games / Simulation models and games in natural resource management (M.: University Humanities Lyceum, 2004).

12. A.V. Lapshova, M.N. Bulaeva, I.R. Voronina, I.E. Barabina, Azimuth of scientific research: pedagogy and psychology, 9 (2020)

13. T. Shimizu, M. Carvalho, F. Laurindo, F., Barbin, The Role of Simulation and Modern Business Games, 11 (2006)

14. J. Tirole, The Theory of Industrial Organization (Cambridge, Mass.: The MIT Press., 1988)

15. J. Apesteguia, G. Azmat, N. Iriberri, Management Science, 58(1), 78-93 (2012) 